\title{
MutL Homolog 1 Measurement
}

National Cancer Institute

\section{Source}

National Cancer Institute. MutL Homolog 1 Measurement. NCI Thesaurus. Code C139094.

The determination of the amount of MutL homolog 1 present in a sample. 